\title{
PENENTUAN PARAMETER EMBOSSING KULIT SINTETIS PVC DENGAN MENGGUNAKAN HIGH FREQUENCY WELDING SHENZEN HIPOWER
}

\author{
Hanky Fransiscus, Cyntiarani Karyoko dan Bagus Made Arthaya \\ Program Studi Teknik Industri, Universitas Katolik Parahyangan \\ e-mail: hanky.fransiscus@unpar.ac.id
}

\begin{abstract}
ABSTRAK
Industri kreatif memiliki kontribusi yang besar bagi perekonomian Indonesia, membuka lapangan kerja baru, serta memperkuat citra dan identitas bangsa. Salah satu bagian dari industri kreatif adalah pengrajin kulit. Produk yang dihasilkan oleh pengrajin cukup bervariasi, seperti dompet, sepatu, tas, dll. Material kulit yang digunakan berupa kulit asli atau kulit sintetis. Salah satu proses dalam menghasilkan produk-produk tersebut adalah embossing untuk membentuk pola hias atau merk. Embossing dapat dilakukan dengan dengan high frequency welding. High frequency welding merupakan penyatuan material dengan menggunakan energi elektromagnetik frekuensi tinggi untuk menghasilkan panas pada material polar sehingga meleleh dan menghasilkan bentuk seperti yang diinginkan setelah proses pendinginan. Laboratorium Proses Produksi Program Studi Teknik Industri memiliki mesin high frequency welding yang dapat digunakan sebagai materi praktikum serta membantu pengrajin kulit kota Bandung, khususnya pengrajin kulit Cibaduyut untuk menghasilkan emboss yang baik. Embossing kulit sintetis dan kulit asli memerlukan parameter proses yang berbeda, hal ini disebabkan sifat fisik setiap jenis kulit. Oleh karena itu diteliti parameter yang tepat untuk menghasilkan emboss kulit sintetis. Penelitian ini menggunakan kulit sintetis yang terbuat dari PVC (Polivinil Klorida). Cetakan yang digunakan merupakan cetakan sederhana berbentuk 2 lingkaran, yaitu lingkaran dalam dan lingkaran luar. Parameter yang diteliti terdiri dari 2 parameter, yaitu suhu dan waktu pengelasan. Eksperimen dilakukan dengan 3 level suhu, yaitu $140^{\circ} \mathrm{C}, 160^{\circ} \mathrm{C}$, dan $170^{\circ} \mathrm{C}$ sedangkan waktu pengelasan dilakukan dengan 3 level yaitu 3 detik, 7 detik, dan 10 detik. Response dari eksperimen ini adalah jari-jari dalam dan jari-jari luar emboss. Hasil proses embossing dipindai dengan menggunakan 3D Scanner dan kemudian dilakukan pengukuran dengan menggunakan perangkat lunak reverse engineering. Pengaruh dari kedua faktor dan interaksinya diketahui dengan menggunakan ANOVA. Pairwise comparison dilakukan dengan menggunakan Tukey's method. Hasil yang diperoleh adalah suhu mempengaruhi response. Berdasarkan percobaan yang dilakukan hasil embossing dengan suhu sebesar $170^{\circ} \mathrm{C}$ lebih baik daripada $140^{\circ} \mathrm{C}$ atau $160^{\circ} \mathrm{C}$.
\end{abstract}

Kata kunci: high frequency welding, design of experiment, kulit sintetis, pvc

\begin{abstract}
Creative industry has lots of contributions to Indonesia's economy, open job fields and strengthen the image and identity of our nation. Leather craft is one part of the creative industry. The final product of this industry can be variety such as wallet, shoes, bag and so on. The material can be genuine leather or faux leather. One of the process to produce those products is embossing for creating pattern or brand. Embossing can be done with high frequency welding. High frequency welding is the process of material unification by using high frequency of electromagnetic energy for generate heat to polar material, hence melt and yield the shape as what it expected after cooling process. Production Process Laboratory of Industrial Engineering Department has high frequency welding machine that can be use as practical material and also support the leather craftsmen in Bandung, especially Cibaduyut leather craft to yield a good emboss. Embossing the genuine and faux leather both require different process parameter due to the differences in each leather's physical characteristics. Therefore, this research is aim to study the precise parameter in order to yield the emboss for faux leather. This research uses faux leather that made from PVC (Polyvinyl Chloride). The mold that being used is a modest mold and in form of two circles which are inner circle and outer circle. There are 2 parameters that studied specifically temperature and welding time. The experiment has been done in 3 levels of temperature which are $140^{\circ} \mathrm{C}, 160^{\circ} \mathrm{C}$, and $170^{\circ} \mathrm{C}$ while the welding time also been done in 3 levels which are 3 seconds, 7 seconds and 10 seconds. The response from this experiment are the inner and outer radius of emboss. The output from emboss process was scanned with $3 D$ scanner and then measured with reverse engineering software. The effect from these two factors and its interaction will be known by using ANOVA. Pairwise comparison was done using Tukey's method. The result shown that temperature affects the response. According to the result of experiment, $170^{\circ} \mathrm{C}$ gives better output comparing to others.
\end{abstract}

Key words:: high frequency welding, design of experiment, faux leather, pvc 


\section{PENDAHULUAN}

Industri kreatif merupakan kegiatan usaha yang fokus poda kreasi dan inovasi. Industri kreatif masih potensial untuk digarap dan Indonesia kaya akan budaya serta tradisi yang menjadi sumber kreativitas [1]. Industri kreatif memiliki kontribusi yang cukup signifikan bagi perekonomian Indonesia. Selain itu, Industri kreatif juga mendukung membuka lapangan kerja baru, serta mampu memperkuat citra dan identitas bangsa Indonesia. Industri kreatif berkontribusi sebesar 6,3\% dari Pendapatan Domestik Bruto dalam perekonomian Indonesia atau stara dengan 152,5 triliun Rupiah pada tahun 2002-2006 [2]. Pada rentang waktu yang sama, industri kreatif menyerap tenaga kerja rata-rata sebesar 5,4 juta atau setara dengan $5,79 \%$ total pekerja yang ada di Indonesia. Selain kedua hal tersebut, industri kreatif juga berperan pada bidang ekspor. Menurut Departemen Perdagangan Republik Indonesia, diestimasi rata-rata total ekspor dari industri kreatif adalah 10,6\% [2].

Saat ini Indonesia merupakan salah satu dari 33 negara yang termasuk dalam jaringan Negara kreatif menurut UNESCO (United Nations Educational, Scientific, and Cultural Organization). Kota di Indonesia yang masuk dalam jaringan kota kreatif dunia UNESCO atau sering disebut dengan UNESCO Creative Cities Network (UCCN) adalah kota Bandung [3]. Kota Bandung menjadi kota kedua di Indonesia yang masuk dalam jaringan kota kreatif dunia UCCN.

Salah satu industri kreatif di kota Bandung adalah industri kreatif sepatu. Setra Industri Sepatu Cibaduyut merupakan penghasil sepatu-sepatu dengan berbagai jenis seperti boots, desert boots, oxford, loafers, sneakers, dan lain-lain. Selain sepatu, Setra Industri Sepatu Cibaduyut juga menghasilkan dompet dan tas. Sebagian besar material yang digunakan di setra industri ini adalah kulit, baik kulit asli atau pun kulit sintetis. Dari kedua material ini, pengrajin cenderung mengunakan kulit sintetis karena harganya yang lebih murah dari kulit asli, akan tetapi memiliki kualitas yang baik. Terdapat 2 jenis kulit sintetis yang umumnya digunakan, yaitu polivinil klorida (PVC) dan poliuretana (PU).
Salah satu fitur pada sepatu, dompet, dan tas berbahan kulit adalah berupa merk berupa tulisan atau logo yang di-emboss. Proses pembuatan produk kulit di Cibaduyut masih dilakukan dengan cara yang sederhana. Proses embossing dilakukan dengan cara hot press. Hot press dilakukan dengan cara memanaskan cetakan dan menekan cetakan ke kulit yang hendak dicetak.

Berdasarkan wawancara dengan pengrajin tradisional di daerah Cibaduyut, persentase kegagalan pada proses embossing pada kulit sintetis lebih besar dibandingkan dengan embossing kulit asli. Hal ini disebabkan kulit sintetis lebih mudah terbakar, sedangkan kulit asli memiliki permukaan yang tidak mudah terbakar. Kulit sintetis mengandung bahan plastik sehingga sangat mudah terbakar ketika terkena panas saat proses pressing. Hal ini menyebabkan proses embossing pada kulit sintetis lebih sulit dilakukan dibandingkan kulit asli.

Teknik embossing lainnya yang dapat dilakukan adalah dengan menggunakan mesin high frequency welding. Salah satu keunggulan dari penggunaan high frequency welding adalah kecepatan yang tinggi dengan energi tinggi yang efisien [4]. Proses embossing dengan mesin high frequency welding dilakukan dengan cara meletakkan kulit sintetis (material dielektrik) di antara dua buah konduktor yang disebut dengan elektroda. Ketika kekuatan frekuensi tinggi lewat di antara kedua elektroda, medan listrik akan terbentuk melewati material dielektrik. Medan listrik yang saling berpindah merangsang molekul dari material dielektrik dan menyebabkan material memanas. Teknik ini memiliki kelebihan dibandingkan dengan teknik pressing karena dapat memanaskan material dari dalam sehingga dapat menghasilkan hasil yang baik dengan kemungkinan kerusakan permukaan kulit lebih kecil.

Laboratorium Proses Produksi, Program Studi Teknik Industri Universitas Katolik Parahyangan memiliki mesin high frequency welding buatan Shenzen Hipower Ltd yang dapat dilihat pada Gambar 1. Mesin ini dapat dimanfaatkan untuk kegiatan praktikum di Program Studi dan membantu pengrajin kulit 
Cibaduyut di kota Bandung. Tindakan awal untuk menghasilkan embossing yang baik adalah perlu dilakukan pengidentifikasian parameter proses. Penelitian ini difokuskan pada proses embossing pada kulit sintetis, khususnya pada material PVC. Oleh karena itu, tujuan dari penelitian ini adalah mengidentifikasi parameter proses yang mempengaruhi hasil embossing pada kulit sintetis PVC dengan menggunakan high frequency welding.

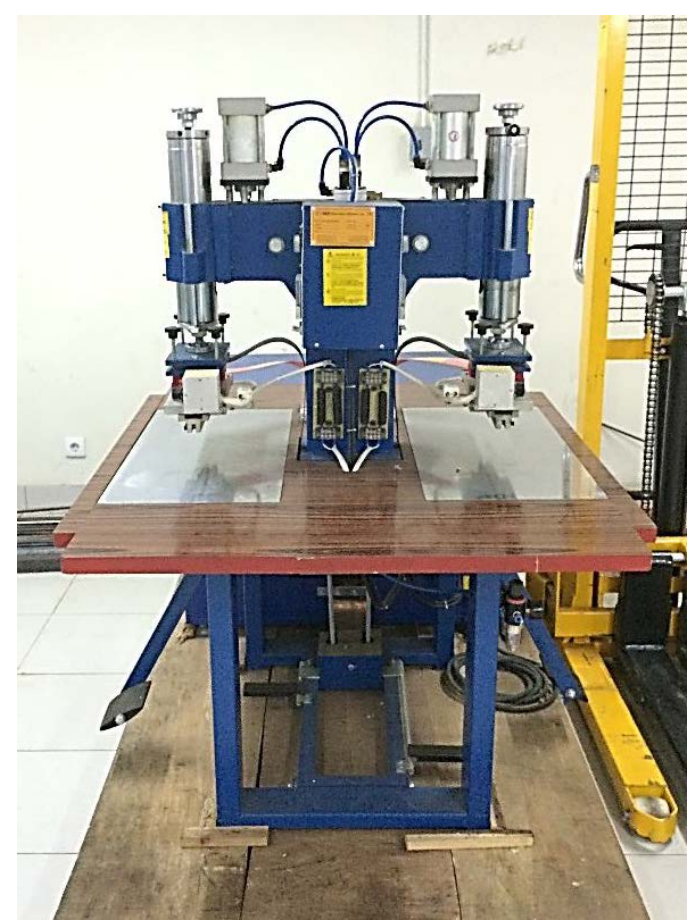

Gambar 1. Mesih High Frequency Welding di Laboratorium Proses Produksi UNPAR

Pendekatan

pemecahan

masalah dilakukan dengan melakukan design of experiment [5]. Penelitian dimulai dengan menentukan output dari penelitian. Penentuan output yang dimaksud adalah menentukan apa yang diukur, bagaimana cara melakukan pengukuran, dan bagaimana hasil pengukurannya. Langkah kedua adalah menentukan faktor yang diteliti. Menurut The Federation of High Frequency Welders [6], terdapat beberapa kontrol mesin yang perlu diperhatikan, yaitu:

\section{Tool Pressure}

Tool pressure merupakan gaya untuk mendorong atau menekan tool ke benda kerja.
Penyetelan ini seringkali diabaikan karena proses pengelasan cukup toleran terhadap gaya tekan tools. Proses pengelasan yang lebih cepat dapat diperoleh dengan menggunakan tekanan yang lebih besar. Tekanan yang diberikan harus cukup bagi tools untuk mempenetrasi benda kerja dalam keadaan panas. Perhatian yang lebih harus diberikan untuk menghindari tekanan yang terlalu besar terutama pada cutand-weld tools.

\section{Press Stroke Adjustment}

Press stroke merupakan jarak vertikal yang akan dilalui oleh plat bagian atas atau toolholder, dimana penyetelannya tergantung pada tipe pengelasan. Dalam proses dimana jarak penglihatan dari benda kerja adalah penting, plat bagian atas harus menempuh jarak yang dapat dilihat secara jelas oleh operator. Dalam proses otomatis atau proses yang menghasilkan jumlah output yang tinggi, jarak yang ditempuh harus dibatasi untuk memperpendek waktu siklus setiap proses.

\section{Depth of Sink Control}

Penyetalan ini sangat penting ketika tidak digunakan tear seal tool. Kontrol sink membatasi seberapa jauh tool akan masuk ke dalam material. Pengaturan pada kontrol ini akan membantu dalam mendapatkan kekuatan las yang optimum.

\section{High Frequency (HF) Power Output}

Tenaga yang disuplai dari generator $H F$ bergantung pada penyetelan dari rangkaian listrik. Penyetelan dari rangkaian listrik tersebut dapat dilakukan melalui kapasitor variabel. Meskipun penyetelan ini mengontrol power output, tidak dimungkinkan untuk dikalibrasi secara langsung karena terdapat variabel lainnya. Perhatian yang tinggi perlu dilakukan untuk mencegah agar tenaga yang digunakan tidak terlalu besar karena dapat merusak benda kerja dan tools. Cara yang paling baik adalah mengatur tenaga mulai dari nol kemudian dengan konstan ditingkatkan hingga besar tenaga yang diinginkan tercapai. Akan lebih baik bila menggunakan tenaga yang lebih kecil dengan waktu yang lebih lama daripada sebaliknya. 


\section{Welding Time}

Waktu pengelasan adalah rentang waktu dimana HF power diaplikasikan dan menimbulkan panas pada benda kerja. Ketika meteran mengindikasikan temperatur dalam benda kerja tidak meningkat lagi, HF power harus segera dimatikan. Hal ini sangat penting karena overheating dapat menyebabkan kerusakan benda kerja baik pada bagian yang dilas, maupun pada area di sekitar area pengelasan.

\section{Cooling Time}

Waktu pendinginan merupakan rentang waktu di antara akhir dari welding time dan pengangkatan welding tool dari benda kerja. Ketika HF power dimatikan, proses pendinginan akan berjalan dengan cepat selama tools masih kontak dengan benda kerja. dalam proses pengelasan dan pendinginan yang berulang-ulang, tools dan lingkungan sekitar menjadi panas sehingga material selanjutnya yang akan dilas memiliki tingkat pendinginan yang lebih rendah. Oleh karena itu, waktu pendinginan harus ditingkatkan untuk penyesuaian.

\section{Platen Temperature}

Dalam mesin welding, untuk mengelas material tebal seperti PVC diperlukan plat yang telah dipanaskan. Dengan menggunakan plat yang telah dipanaskan, panas yang hilang dari material benda kerja akan berkurang sehingga memungkinkan area yang lebih luas untuk dilas dengan $H F$ power yang tersedia. Dan juga dikarenakan suhu plat relatif lebih tinggi dibandingkan dengan suhu lingkungan dan terkontrol secara termostat, fluktuasi dari suhu lingkungan dapat diabaikan.

\section{METODE PENELITIAN}

Berdasarkan tinjauan pustaka yang telah dilakukan, High Frequency Welding umumnya terdiri dari 7 kontrol mesin yang harus diperhatikan. Akan tetapi High Frequency Welding Shenzen Hipower hanya memiliki beberapa bagian yang dapat diatur dengan mudah, yaitu welding time dan suhu. Setelah faktor eksperimen diketahui, dilakukan penentuan level pada setiap faktor. Penentuan level dilakukan dengan melakukan percobaan pendahuluan, yaitu dengan mecoba beberapa level yang mungkin untuk dilakukan. Berdasarkan penelitian pendahuluan dipilihlah 3 buah level pada setiap faktor, yaitu level yang rendah, sedang, dan tinggi. Langkah ketiga adalah melakukan pengambilan data dengan kombinasi level secara acak. Hasil percobaan kemudian diukur dan dianalisa dengan menggunakan Analysis of Variance (ANOVA). Kesimpulan yang dapat diperoleh dari ANOVA kemudian dianalisa sehingga dapat diketahui kombinasi level yang menghasilkan hasil atau response terbaik dari percobaan yang dilakukan. Metodologi ini dapat dilihat pada Gambar 2.

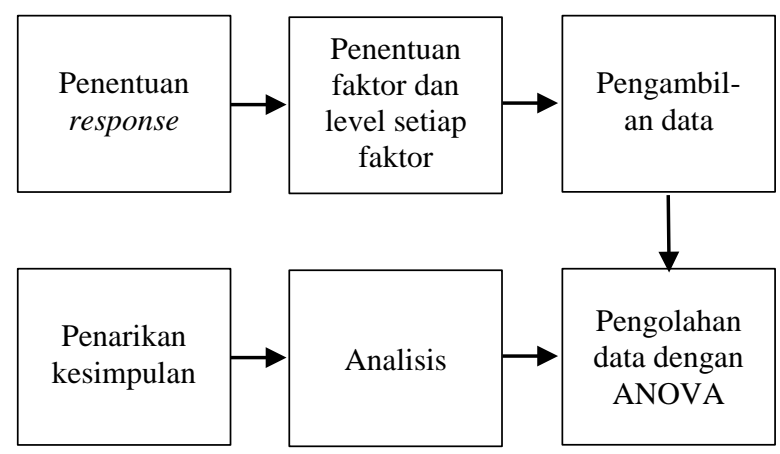

Gambar 2. Metodologi Penelitian

\section{HASIL DAN PEMBAHASAN}

Penelitian ini menggunakan sebuah cetakan yang berbentuk 2 buah lingkaran sepusat. Cetakan tersebut terbuat dari material aluminium. Pengukuran dilakukan untuk mengetahui jari-jari kedua lingkaran tersebut (lingkaran dalam dan lingkaran luar). Pengukuran dilakukan dengan jangka sorong digital dan cetakan diletakkan di atas meja rata. Sebelum dilakukan pengukuran, benda diletakkan selama kurang lebih sepuluh menit dan tidak disentuh agar tidak terjadi pemuaian cetakan akibat suhu tubuh manusia. Pengukuran dilakukan pada suhu kamar. Pengukuran dilakukan berkali-kali agar diperoleh hasil yang akurat. Pada penelitian ini dilakukan pengukuran sebanyak 10 kali. Berdasarkan hasil pengukuran diperoleh jari-jari lingkaran dalam dan lingkaran luar secara berturut-turut sebesar 14,388 mm dan 25,192 mm. Cetakan ini kemudian digunakan untuk menghasilkan kulit PVC dengan fitur emboss. 
Kualitas emboss dapat diukur dengan 2 cara, yaitu secara kualitatif dan secara kuantitatif. Pengukuran secara kualitatif berarti dilakukan penilaiai oleh expert, sedangkan pengukuran secara kuantitatif dilakukan dengan menggunakan alat ukur. Pengukuran pada penelitian ini dilakukan secara kuantitatif karena bentuk cetakan yang sangat sederhana. Response pada penelitian ini adalah jari-jari lingkaran hasil proses embossing. Setelah diketahui berapa jari-jari dari hasil embossing, maka dapat diketahui seberapa dekat jari-jari hasil embossing dengan jari-jari cetakan. Semakin dekat ukuran hasil proses embossing dengan ukuran cetakan artinya hasil yang diperoleh dapat dikatakan semakin baik.

Setelah diketahui response dari eksperimen langkah selanjutnya adalah menentukan faktor dan level dari eksperimen. Seperti telah dijelaskan pada metodologi penelitian, faktor dari penelitian ini adalah welding time dan temperature. Pengoperasian mesin ini sangat sederhana. Dengan menekan pedal pada mesin, maka cetakan akan turun dan menekan material selama waktu yang ditentukan. Setelah mencapai waktu yang ditentukan maka lampu penanda akan menyala dan operator harus melepaskan pedal. Oleh karena itu operator harus memperhatikan dengan baik dan dalam kondisi terjaga yang baik. Karena keterbatasan operator melihat perubahan lampu penanda, maka waktu pengelasan minimum adalah 3 detik. Waktu pengelasan maksimum pada mesin ini adalah 10 detik,oleh karena itu waktu pengelasan maksimum adalah 10 detik. Sementara waktu pengelasan sedang adalah 7 detik.

Berdasarkan penelitian pendahuluan pula, hasil pengelasan mulai terlihat secara samar pada suhu $130^{\circ} \mathrm{C}$ dan kulit terkelupas ketika suhu pengelasan sebesar $180^{\circ} \mathrm{C}$. Apabila suhu pengelasan sebesar $170^{\circ} \mathrm{C}$ secara kasat mata terlihat hasil yang baik. Oleh karena itu, level suhu tinggi pada penelitian ini adalah $170^{\circ} \mathrm{C}$, level sedang adalah $160^{\circ} \mathrm{C}$, dan level rendah adalah $140^{\circ} \mathrm{C}$. Hasil proses embossing pada kulit PVC dengan menggunakan high frequency welding machine dapat dilihat pada Gambar 3.

Berdasarkan kedua faktor dengan 3 level pada setiap faktor, maka terdapat 9 kombinasi level yang diteliti. Pengambilan data dilakukan dengan kombinasi level acak. Setiap kombinasi dilakukan pengulangan (replikasi) sebanyak 5 kali. Jari-jari hasil embossing diukur dengan menggunakan 3D Scanner Creaform HandySCAN 300 (Gambar 4(a)). Hasil dari pemindaian dengan menggunakan 3D Scanner ini sangat akurat. Akurasi dari 3D Scanner ini adalah 0,040 $\mathrm{mm}$ [7]. Hasil pemindaian (Gambar 4(b)) kemudian diukur dengan menggunakan perangkat lunak reverse engineering.

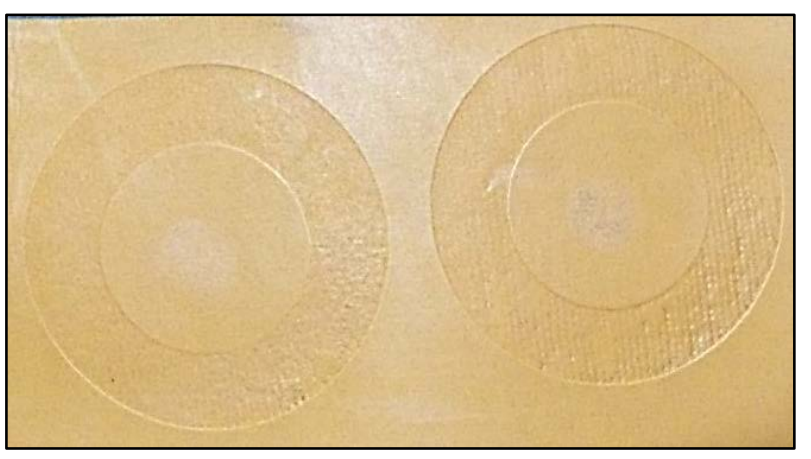

Gambar 3. Contoh Emboss dengan

Menggunakan High

Frequency Welding Machine

Pengujian statistik dilakukan untuk mengetahui kepresisian dari alat ukur. Dilakukan pengukuran terhadap 5 hasil embossing dengan treatment yang sama. Setiap emboss diukur sebanyak 8 kali. Berdasarkan pengujian secara statistik dengan menggunakan ANOVA, tidak terdapat perbedaan antara pengukuran pertama sampai dengan pengukuran kedelapan. Hal ini menunjukkan $3 D$ Scanner dapat melakukan pemindaian secara presisi.

Setelah diketahui pengukuran dilakukan dengan akurat dan presisi, dilakukan pengambilan dan pengolahan data untuk mengetahui apakah suhu dan waktu pengelasan mempengaruhi ukuran hasil embossing. Hasil pengujian ANOVA untuk lingkaran dalam ditunjukkan pada Tabel 1. Sedangkan hasil pengujian ANOVA untuk lingkaran luar ditunjukkan pada Tabel 2.

Berdasarkan kedua pengujian di atas dapat diperoleh kesimpulan bahwa faktor suhu mempengaruhi jari-jari lingkaran dalam maupun luar dari hasil embossing. Sedangkan 
waktu pengelasan dan suhu tidak mempengaruhi response. Dengan demikian perlu dilakukan perbandingan berpasangan antar level pada faktor suhu pengelasan. Salah satu metode perbandingan berpasangan adalah Tukey Pairwise Comparisons [8].

Tabel 1. Selisih Jari-jari Emboss dengan Cetakan dengan Memperhatikan\ Suhu

\begin{tabular}{lcccc}
\hline & $\begin{array}{c}\text { Suhu } \\
\left({ }^{\circ} \mathrm{C}\right)\end{array}$ & $\begin{array}{c}\text { Jari-jari } \\
\text { Emboss } \\
(\mathrm{mm})\end{array}$ & $\begin{array}{c}\text { Jari-jari } \\
\text { Cetakan } \\
(\mathrm{mm})\end{array}$ & $\begin{array}{c}\text { Selisih } \\
(\mathrm{mm})\end{array}$ \\
\hline \multirow{2}{*}{ Lingkaran } & 170 & 14.613 & 14.388 & $(1)-(2)$ \\
\hline Dalam & 150 & 14.746 & 14.388 & $0.225^{*}$ \\
& 140 & 14.835 & 14.388 & 0.447 \\
\hline \multirow{2}{*}{ Lingkaran } & 170 & 24.915 & 25.192 & $-0.277^{*}$ \\
Luar & 150 & 24.801 & 25.192 & -0.391 \\
& 140 & 24.719 & 25.192 & -0.473 \\
\hline
\end{tabular}

*) Selisih terdekat antara jari-jari emboss dengan jari-jari cetakan

Tabel 2. Selisih Jari-jari Emboss dengan Cetakan dengan Suhu $170^{\circ} \mathrm{C}$

\begin{tabular}{lccc}
\hline & $\begin{array}{c}\text { Waktu } \\
\text { (detik) }\end{array}$ & $\begin{array}{c}\text { Jari-jari } \\
\text { Emboss } \\
(\mathrm{mm})\end{array}$ & $\begin{array}{c}\text { Selisih dengan } \\
\text { Cetakan }(\mathrm{mm})\end{array}$ \\
\hline Lingkaran & 10 & 14.5456 & $0.1576^{*}$ \\
Dalam & 7 & 14.6671 & 0.2791 \\
& 3 & 14.6265 & 0.2385 \\
\hline \multirow{2}{*}{ Lingkaran } & 10 & 24.9541 & $-0.2379^{*}$ \\
Luar & 7 & 24.9052 & -0.2868 \\
& 3 & 24.8865 & -0.3055 \\
\hline
\end{tabular}

*) Selisih terdekat antara jari-jari emboss dengan jari-jari cetakan

Tabel 3. Hasil Pengujian ANOVA untuk Lingkaran Dalam

\begin{tabular}{|c|c|c|c|c|c|}
\hline Source & DF & Adj SS & Adj MS & $\begin{array}{l}\text { F- } \\
\text { Value }\end{array}$ & $\begin{array}{l}\text { P- } \\
\text { Value }\end{array}$ \\
\hline Suhu & 2 & 0,37407 & 0,187035 & 6,11 & 0,005 \\
\hline Waktu & 2 & 0,00118 & 0,000589 & 0,02 & 0,981 \\
\hline Suhu*Waktu & 4 & 0,07725 & 0,019314 & 0,63 & 0,644 \\
\hline Error & 36 & 1,10202 & 0,030612 & & \\
\hline Total & 44 & 1,55452 & & & \\
\hline
\end{tabular}

Tabel 4. Hasil Pengujian ANOVA untuk Lingkaran Luar

\begin{tabular}{llllrl}
\hline Source & \multirow{2}{*}{ DF } & Adj SS & Adj MS & $\begin{array}{l}\text { F- } \\
\text { Value }\end{array}$ & $\begin{array}{l}\text { P- } \\
\text { Value }\end{array}$ \\
\hline Suhu & 2 & 0,29217 & 0,146085 & 9,98 & 0,000 \\
Waktu & 2 & 0,07018 & 0,035088 & 2,40 & 0,105 \\
Suhu*Waktu & 4 & 0,03251 & 0,008127 & 0,56 & 0,696 \\
\hline Error & 36 & 0,52686 & 0,014635 & & \\
\hline Total & 44 & 0,92172 & & & \\
\hline
\end{tabular}

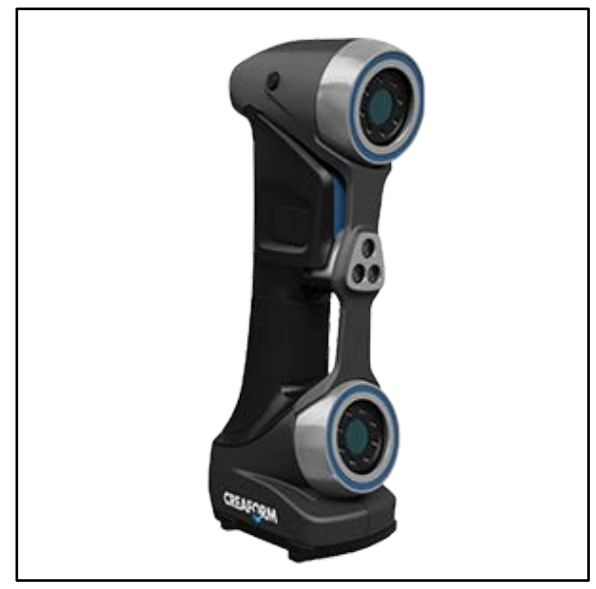

(a)

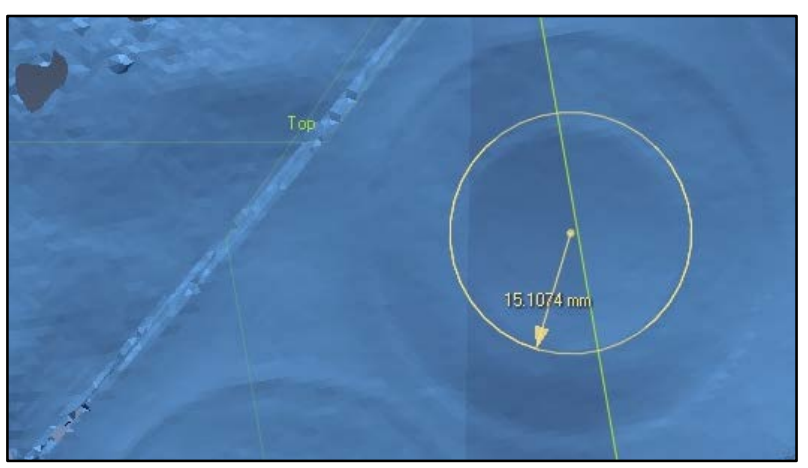

(b)

Gambar 4. (a) 3D Scanner Creaform Handy SCAN 300 (b) Hasil Pemindaian

Tukey Pairwise Comparisons:

Response $=\mathrm{R}$ dalam, Term $=$ Suhu

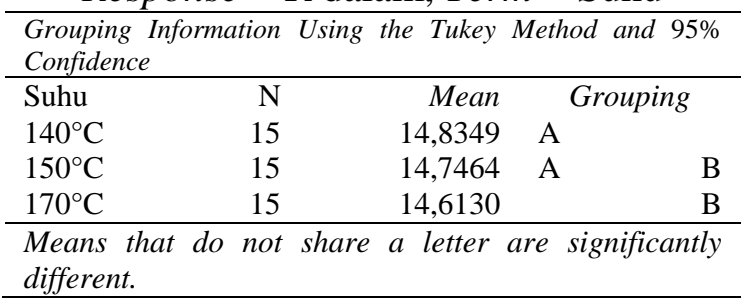

Tukey Pairwise Comparisons:

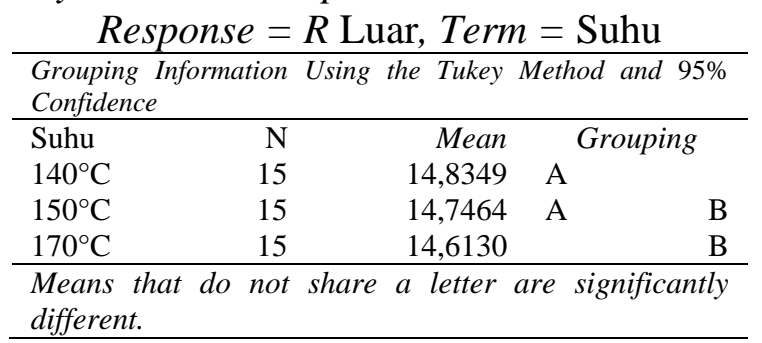

Berdasarkan pengujian perbandingan berpasangan di atas, diketahui bahwa ada perbedaan jari-jari dalam dan jari-jari luar yang signifikan apabila menggunakan suhu pengelasan $140^{\circ} \mathrm{C}$ dan $170^{\circ} \mathrm{C}$. Hasil yang 
dianggap baik adalah apabila jari-jari emboss mendekati jari-jari cetakan. Berdasarkan Tabel 1 dapat dilihat bahwa apabila suhu pengelasan sebesar $170^{\circ} \mathrm{C}$ digunakan, maka ukuran emboss mendekati ukuran cetakannya. Sebaliknya apabila suhu yang lebih rendah digunakan, maka selisih antara jari-jari emboss dengan jarijari cetakan semakin besar.

High frequency welding menggunakan tegangan yang tinggi untuk menggetarkan molekul-molekul pada benda kerja (kulit sitetis) sehingga menimbilkan panas secara internal dan meningkatkan pergerakan rantai polimer. Oleh karena bentuk cetakan yang memiliki fitur lingkaran dalam dan lingkaran luar, maka ketika cetakan menekan kulit sintetis, molekul kulit bergerak ke dalam dan ke luar lingkaran. Kulit kemudian mengalami perubahan bentuk yang permanen sesuai dengan bentuk cetakan. Suhu yang tinggi menghasilkan energi yang lebih besar untuk mendorong molekul, sehingga molekul membentuk ukuran yang sesuai dengan ukuran cetakan.

Walaupun pengujian ANOVA menunjukkan tidak terjadi perbedaan hasil yang signifikan apabila dilakukan pengaturan waktu pengelasan, akan tetapi apabila dipetakan dengan menggunakan statistika deskriptif, maka pada suhu $170^{\circ} \mathrm{C}$, waktu pengelasan yang jarijari emboss paling mendekati jari-jari cetakan adalah 10 detik.

\section{KESIMPULAN}

Berdasarkan pengolahan data di atas dapat ditarik kesimpulan bahwa faktor yang mempengaruhi ukuran emboss adalah suhu. Suhu yang direkomendasikan agar dapat menghasilkan emboss yang ukurannya mendekati ukuran cetakan adalah $170^{\circ} \mathrm{C}$.

\section{DAFTAR PUSTAKA}

[1] Saedah, E., "Industri Kreatif Masih Potensial”, http://www.kemenperin.go.id/ artikel/ 4060/ Industri-Kreatif-MasihPotensial, diakses 15 Agustus 2016.
[2] Departemen Perdagangan Republik Indonesia, 2008, Pengembangan Ekonomi Kreatif Indonesia 2025: Rencana Pengembangan Ekonomi Kreatif Indonesia 2009-2015, Departemen Perdagangan RI, Indonesia.

[3] UNESCO, "Creative Cities Network", http://en.unesco.org/creative-

cities/creative-cities-map, diakses 15 Agustus 2016.

[4] American Welding Society, 2007, Welding Handbook, Ninth edition, American Welding Society, United States of America.

[5] Shankar, R., 2009, Process Improvement Using Six Sigma: A DMAIC Guide. ASQ Quality Press, United States of America.

[6] Federation of High Frequency Welders, 2001, High Frequency Welding Handbook, The Federation of High Frequency Welders, United Kingdom.

[7] Creaform, "Metrology: Creaform”, https://www.creaform3d.com/en/metrolog y-solutions/portable-3d-scannerhandyscan-3d, diakses 14 Februari 2017.

[8] Montgomery, D. C., 2009, Introduction to Statistical Quality Control. Sixth edition, John Wiley \& Sons, Inc., United States of America. 